\title{
DETERMINATION OF POLYPHENOLS IN SPANISH WINES BY CAPILLARY ZONE ELECTROPHORESIS. APPLICATION TO WINE CHARACTERIZATION BY USING CHEMOMETRICS.
}

\begin{tabular}{|r|l|}
\hline Journal: & Journal of Agricultural and Food Chemistry \\
\hline Manuscript ID: & jf-2012-02078j.R1 \\
\hline Manuscript Type: & Article \\
\hline Date Submitted by the Author: & $\mathrm{n} / \mathrm{a}$ \\
\hline Complete List of Authors: & $\begin{array}{l}\text { Franquet-Griell, Helena; University of Barcelona, } \\
\text { Checa, Antonio; University of Barcelona, } \\
\text { Nunez, Oscar; University of Barcelona, Analytical Chemistry } \\
\text { Saurina, Javier; University of Barcelona, Analytical Chemistry } \\
\text { Hernández-Cassou, Santiago; University of Barcelona, } \\
\text { Puignou, Lluis; UNIVERSITAT DE BARCELONA, ANALYTICAL CHEMISTRY }\end{array}$ \\
\hline \hline
\end{tabular}


5 DETERMINATION OF POLYPHENOLS IN SPANISH WINES BY 6 CAPILLARY ZONE ELECTROPHORESIS. APPLICATION TO WINE 7 CHARACTERIZATION BY USING CHEMOMETRICS.

9 Helena Franquet-Griell, Antonio Checa, Oscar Núñez, Javier Saurina, Santiago

10 Hernández-Cassou, Lluis Puignou

Department of Analytical Chemistry, University of Barcelona. Martí i Franquès, 1-11, 13 E-08028 Barcelona. Spain.

* Corresponding author: Oscar Núñez

19 Department of Analytical Chemistry, University of Barcelona.

20 Martí i Franquès, 1-11, E-08028 Barcelona, Spain.

21 Phone: 34-93-402-1286

22 Fax: 34-93-402-1233

23

e-mail: oscar.nunez@ub.edu

24 
Abstract

A capillary zone electrophoresis method for the simultaneous determination of twenty polyphenols in wine was developed. The separation was performed using fused-silica capillaries of $75 \mu \mathrm{m}$ I.D. and a $30 \mathrm{mM}$ sodium tretraborate buffer solution at $\mathrm{pH} 9.2$ with $5 \%$ isopropanol as a background electrolyte. A capillary voltage of $+25 \mathrm{kV}$ with pressure-assisted $(3.5 \mathrm{kPa})$ separation from min 18 was applied, thus, achieving a total analysis time lower than $20 \mathrm{~min}$. Instrumental quality parameters such as limits of detection (LOD values between 0.3 and $2.6 \mathrm{mg} / \mathrm{L})$, linearity $\left(\mathrm{r}^{2}>0.990\right)$, and run-to-run and day-to-day precisions (RSD values lower than 6.5\% and $15.7 \%$, respectively) were established. Three different calibration procedures were evaluated for polyphenol quantitation in wines: external calibration using standards prepared in Milli-Q water, standard addition, and pseudo-matrix matched calibration using wine as a matrix. For a 95\% confidence level, no statistical differences were observed, in general, between the three calibration methods ( $p$-values between 0.11 and 0.84 ), while for some specific polyphenols, such as cinnamic acid, syringic acid and gallic acid, results were not comparablewhen external calibration used. CZE method using pseudo-matrix matched calibration was then proposed and applied to the analysis of polyphenols in 49 Spanish wines, showing satisfactory results and a wide compositional variation between wines. Electrophoretic profiles and other compositional data (e.g., peak areas of selected peaks) were considered as fingerprints of wines to be used for characterization and classification purposes. The corresponding data were analyzed by PCA in order to extract information on the most significant features contributing to wine discrimination according to their origins. Results showed that a reasonable distribution of wines depending on the elaboration areas was found, being tirosol, gallic, protocatechuic, pcoumaric and caffeic acids some representative discriminant compounds. 


\section{INTRODUCTION}

Moderate consumption of wine has been associated with reduced risk of cardiovascular diseases and cancer, as well as with several beneficial effects on the human immune system and cognitive functions (1). Health-promoting properties such as anti-oxidant, anti-bacterial, anti-inflammatory, anti-allergic and anti-thrombotic activities have been related with the presence of polyphenols (2). Other phenolic compounds, such as phenolic acids, catechins and some flavonoids play an important role in wine quality, contributing in flavor and color properties, especially on red wines $(3,4)$. Thus, the determination of polyphenols in wines, using reliable methods, for quality control and assessment of wines because of their effects on health and taste of these products is considered at the moment a priority.

High performance liquid chromatography (HPLC) has been the technique of choice for the quantification of phenolic compounds in wine using either UV absorption spectroscopy (5-12) or mass spectrometry (LC-MS) $(13,14)$. Other analytical techniques such as gas chromatography coupled to mass spectrometry (15), polycyclic sensors $(16,17)$ or cyclic voltammetry $(18)$ have also been recently reported for the analysis of these compounds.

Lately, the utilization of capillary electrophoresis (CE) has increased as an alternative to LC because of his high efficiency, rapid analysis and low reagent consumption. The application of $\mathrm{CE}$ to the determination of phenolic compounds in beverages (19) and foods (20,21), including wine, has been reviewed. A specific revision of methods for quantifying resveratrol in wine is also given elsewhere (22). For instance, capillary zone electrophoresis (CZE) methods using phosphate or borate-based electrolytes has been described for the quantitative analysis of phenolic acids (23-28), resveratrol $(26,29)$, flavonols $(26,30)$, catechins $(27-30)$, and different flavonoids $(24,31)$. Other CE techniques, such as micellar electrokinetic chromatography (MEKC) with sodium dodecyl sulfate (SDS) have also been applied to the determination of phenolic acids $(32,33)$ and flavonoids $(32-34)$. However, from the point of view of wine analysis, no more than 10 common polyphenols are usually quantifyed in many of these works. Some of these CE studies focused solely on the determination of the phytoalexin resveratrol (35-37). Detections often rely on UV spectroscopy using diode array devices, but other techniques such as voltammetry (29), or CE coupled to mass spectrometry (CE-MS) (14) have also been employed. 
Obtaining reliable quantitative data for the quantification of polyphenols in wine using capillary electrophoresis is still necessary. For instance, some comparisons between the quantitative performance of HPLC and CE methods have been carried out. In some studies, no significant qualitative and quantitative differences in the results were obtained by the two techniques (28). In other cases, small differences were reported $(30,31)$. For this reason, different calibration procedures must be evaluated for polyphenol quantitation in wine samples by $\mathrm{CE}$.

The characterization and classification of wines can be tacked from compositional profiles as a source of analytical information. Families of natural wine components such as low molecular organic acids, alcohols, esters, polyphenols, amino acids, biogenic amines and inorganic species have been found to be efficient descriptors of some climatic, agricultural and oenological features. Hence, such compositional data can be treated by chemometric methods such as principal component analysis (PCA) and partial least square regression (PLS) and discriminant analysis (DA) for classification, quantification and authentication purposes (38).

118 This work was aimed at developing and evaluating a CZE method for the 119 simultaneous determination of 20 polyphenols in wine, without any sample treatment. 120 Quality parameters, such as limits of detection (LODs), limits of quantitation (LOQs), 121 linearity, and run-to-run and day-to-day precisions were established by using two 122 different CE instruments. Three calibration procedures (external calibration, standard 123 addition and pseudo-matrix matched calibration) were also evaluated and compared for 124 the analysis of polyphenols in wine samples. The proposed CZE method was applied to the quantification of polyphenols in various Spanish wines. Contents of representative compounds were exploited as potential descriptors of geographical region of wines.

127 Graphs of the wine distribution obtained by using PCA showed significant clustering as 128 a function of origin.

\section{MATERIALS AND METHODS}

\section{Reagents and solutions}

Syringic acid, $p$-coumaric acid, homovanillic acid, protocatechuic acid, resveratrol, fisetin, (-)-epicatechin, quercitrin hydrate, and 4-hydroxybenzoic acid

136 standards of analytical grade were obtained from Sigma-Aldrich (Steinheim, Germany). 
137 2-(4-hydroxyphenyl)ethanol (Tyrosol), trans-cinnamic acid, gallic acid, veratric acid,

138 homogentistic acid, caffeic acid, sinapic acid, ferulic acid, vanillin, and (+)-catechin

139 were purchased from Fluka (Steinheim, Germany), and quercetin dihydrate was from

140 Riedel-de Haën (Seelze, Germany).

141 HPLC-gradient grade methanol and isopropanol were obtained from Merck

142 (Darmstadt, Germany), and sodium tetraborate was purchased from Sigma-Aldrich.

143 Stock standard solutions of all polyphenols $(\sim 1000 \mathrm{mg} / \mathrm{L})$ were prepared in

144 methanol. Intermediate working solutions were prepared weekly from these stock

145 standard solutions by appropriate dilution with water. All stock solutions were stored at

$1464{ }^{\circ} \mathrm{C}$ for not more than 1 month. Background electrolyte (BGE) was prepared daily by

147 dilution of a $100 \mathrm{mM}$ sodium tetraborate solution, and adding the appropriate amount of

148 isopropanol. BGE solutions were filtered through $0.45 \mu \mathrm{m}$ nylon filters (Whatman,

149 Clifton, NJ, USA).

150 Water was purified using an Elix 3 coupled to a Milli-Q system (Millipore,

151 Bedford, MA, USA) and filtered through a $0.22 \mu \mathrm{m}$ nylon filter integrated into the

152 Milli-Q system.

153

154 Apparatus

155

The experiments were performed on a Beckman P/ACE MDQ capillary electrophoresis system (Fullerton, CA, USA) equipped with a diode array detection system. The electrophoretic separation was carried out using uncoated fused silica capillaries (Beckman) with a total length of $60 \mathrm{~cm}$ (effective length $50 \mathrm{~cm}$ ) x $75 \mu \mathrm{m}$ I.D.

160 The background electrolyte (BGE) consisted of $30 \mathrm{mM}$ sodium tetraborate buffer 161 solution ( $\mathrm{pH} 9.2)$ containing $5 \%(\mathrm{v} / \mathrm{v})$ isopropanol. Capillary temperature was held at 25 $162{ }^{\circ} \mathrm{C}$. The BGE was filtered through a $0.45 \mu \mathrm{m}$ membrane filter, and degassed by 163 sonication before use. Samples were loaded by pressure-assisted hydrodynamic 164 injection $(10 \mathrm{~s}, 3.5 \mathrm{kPa})$. The electrophoretic separation of polyphenols was performed 165 by applying a capillary voltage of $+25 \mathrm{kV}$. Pressure-assisted separation (3.5 kPa) from 166 minute 18 was used. Direct UV absorption detection was carried out from $190 \mathrm{~nm}$ to $167310 \mathrm{~nm}$ (sample quantitation was performed at $280 \mathrm{~nm}$ ). This CE instrument was 168 controlled using a Beckman 32 Karat software version 5.0. Peak integration was 169 performed valley-to-valley taking into account the baseline shift showed in the 170 electropherograms. 
To study the method performance, a Beckman P/ACE 5500 CE System

172 (Beckman) was also used. With this instrument, a fused silica capillary with a total 173 length of $57 \mathrm{~cm}$ (effective length $50 \mathrm{~cm}$ ) x $75 \mu \mathrm{m}$ I.D. was used. This CE instrument 174 was controlled using a Beckman P/ACE station software version 1.2. All other acquisition conditions were equal to those of MDQ CE instrument.

\section{Capillary conditioning}

New capillaries were pretreated with $0.1 \mathrm{M}$ hydrochloric acid for $60 \mathrm{~min}$, water for $60 \mathrm{~min}, 0.1 \mathrm{M}$ sodium hydroxide for $60 \mathrm{~min}$, and finally they were washed with water for $60 \mathrm{~min}$. At the beginning of each working session, the capillary was rinsed with sodium hydroxide for $30 \mathrm{~min}$, water for $30 \mathrm{~min}$, and with the BGE for $60 \mathrm{~min}$. The capillary was rinsed with BGE for 5 min between runs. At the end of each session, the capillary was stored after rinsing with water.

\section{Data Analysis}

MATLAB (Version 6.5) was used for calculations. PCA was from the PLSToolbox (39). A detailed description of this method is given elsewhere (40).

The plot of scores showing the distribution of the samples on the principal components (PCs) may reveal patterns that may be correlated to sample characteristics, in this case sample origin. The study of the distribution of variables (loadings' plot) provided information dealing with their correlations and possible relationships with wine properties. Additionally, the simultaneous study of the scores and loadings (biplot) was used to explore the relationships between samples and variables.

\section{Samples}

A total of 102 red wines were purchased from a supermarket in Barcelona, Spain. These wines were chosen in two batches: (i) one of 49 wines chosen to get a variety of wines produced in several regions of Spain to establish the CZE method, and (ii) another of 53 wines chosen from three selected Spanish regions (Catalunya, La Rioja and Castilla - La Mancha) to study wine characterization according to their region of origin. All wines were analyzed from freshly opened bottles; determinations were 
always done in less than 48 hours to preserve polyphenol content. Samples were directly injected into the CE system after a filtration step using $0.45 \mu$ m nylon filters (the first 1 $2 \mathrm{~mL}$ of filtrate were rejected). No further sample treatment was performed. The analytes were identified by comparison of the migration times with those of aqueous standards as well as those obtained by spiking the wines with standards.

210

\section{RESULTS AND DISCUSSION}

212

\section{Optimization of the separation}

As it has been mentioned in the introduction, most of the works dealing with analysis of polyphenols in wines by CE have been focused on a few compounds (the most abundant ones). However, for wine characterization and better understanding of health-promoting properties, it can be interesting to study the presence of other polyphenols although they may not occur at relatively high concentrations. For this reason, in this study a CZE method was developed for the simultaneous separation and determination of 20 polyphenols in red wines. Borate-based buffers were chosen as BGE for the electrophoretic separation as they provided $\mathrm{pH}$ values around 9.2, making them suitable for the separation of this family of compounds in positive polarity mode. However, the addition of organic solvents is mandatory to improve the electrophoretic separation. In this work, a solution of sodium tetraborate containing isopropanol as organic modifier was selected as BGE separation. The optimization of the percentage of organic solvent and electrolyte concentration in the running buffer relied on experimental design. A standard mixture containing the 20 polyphenolic compounds under study was prepared to evaluate the performance of the separation. In this case, a 2 -factor grid design was defined. Concentrations of isopropanol and borate buffer were assayed at 5 levels (from 1 to 5\%, in steps of 1\%) and 3 levels (10, 20 and $30 \mathrm{mM}$ ), respectively. As a result, a total of $5 \times 3$ experiments were carried out. The criterion for finding the optimal experimental conditions was based on obtaining the best separation, in terms of number of resolved peaks $\left(N_{\text {peaks }}\right)$ and resolution $\left(\mathrm{R}_{\mathrm{s}}\right)$, in the minimum run time $\left(t_{\text {run }}\right)$. Figure 1 shows the response surfaces obtained for each of the objectives considered. In the case of $N_{\text {peaks }}$, the maximum was achieved at 5\% isopropanol and 30 $\mathrm{mM}$ borate buffer. For $\mathrm{R}_{\mathrm{s}}$ of $p$-coumaric and quercetin peaks, two maxima were found 
239 was estimated from the migration time of the last peak of the electropherogram $(2,3-$ 240 dihydroxybenzoic acid), the faster runs were obtained at $1 \%$ isopropanol and $10 \mathrm{mM}$ 241 borate.

242 In order to reach a suitable compromise among these 3 objectives, a combined desirability response was defined as follows: $D=\left(d_{\text {peaks }} \times d_{\text {res }} \times d_{\text {time }}\right)^{1 / 3}$, being $d_{\text {peaks }}, d_{\text {res }}$

244 and $\mathrm{d}_{\text {time }}$ the normalized (desirability) contributions of $N_{\text {peaks, }}, \mathrm{R}_{\mathrm{s}}$ and $\mathrm{t}_{\text {run, }}$, respectively. 245 Experimental values of $N_{\text {peaks }}, \mathrm{R}_{\mathrm{s}}$ and $\mathrm{t}_{\text {run }}$ were used to estimate the corresponding 246 individual desirabilities according to the following transformations: (i) $d_{\text {peaks }}=0$ for $247 N_{\text {peaks }} \leq 10, \mathrm{~d}_{\text {peaks }}=1$ for $N_{\text {peaks }}=20$, and $0<\mathrm{d}_{\text {peaks }}<1$ for $10<N_{\text {peaks }}<20$; (ii) $\mathrm{d}_{\text {res }}=0$ 248 for $\mathrm{R}_{\mathrm{s}} \leq 0.7, \mathrm{~d}_{\text {res }}=1$ for $\mathrm{R}_{\mathrm{s}} \geq 1.5$, and $0<\mathrm{d}_{\text {res }}<1$ for $0.7<\mathrm{R}_{\mathrm{s}}<1.5$; (iii) $\mathrm{d}_{\text {time }}=0$ for $249 \mathrm{t}_{\text {run }} \geq 45 \mathrm{~min}, \mathrm{~d}_{\text {time }}=1$ for $\leq 10 \mathrm{~min} \mathrm{R}_{\mathrm{s}}$, and $0<\mathrm{d}_{\text {time }}<1$ for $45<\mathrm{t}_{\text {run }}<10$, depicts the 250 overall desirability $\mathrm{D}$. The maximum values of this surface were attained at $5 \%$ 251 isopropanol and $30 \mathrm{mM}$ borate buffer so these experimental conditions were selected as 252 optimal. Under these conditions, analytes were separated in about $40 \mathrm{~min}$ by applying $253+25 \mathrm{kV}$. An increase in capillary voltage was not useful to reduce analysis time because 254 the electrophoretic separation worsened significantly. However, as the last migrating 255 polyphenols 4-hydroxybenzoic acid, caffeic acid, gallic acid and 3,4-dihydroxybenzoic 256 acid (peaks 17 to 20, respectively) presented a high separation, an over-imposed 257 pressure of $3.5 \mathrm{kPa}$ was applied at min 18 to reduce the analysis time. Separation was 258 then accomplished in less than 25 min. Figure 2 shows the electropherogram of a 30 $259 \mathrm{mg} / \mathrm{L}$ standard of all polyphenols obtained under optimal conditions: $30 \mathrm{mM}$ tetraborate 260 buffer with $5 \%$ isopropanol as BGE, separation at $+25 \mathrm{kV}$, and pressure assisted 261 separation $(3.5 \mathrm{kPa})$ from min 18. Although some pairs of compounds were not baseline 262 separated (pairs 3/4, 8/9 and 15/16 with resolutions of $0.7,0.8$ and 1.0, respectively), the 263 separation can be considered acceptable as a compromise between resolution and 264 analysis time. Hydrodynamic injection time ( 2 to $25 \mathrm{~s}$ ) was also studied in order to 265 increase sensitivity. An injection time of $10 \mathrm{~s}(3.5 \mathrm{kPa})$ was selected as an optimal 266 compromise between peak signal and resolution.

\section{Instrumental quality parameters}

Instrumental quality parameters of the proposed CZE method under optimal conditions were evaluated using two $\mathrm{CE}$ instruments. Figures of merit are given in 
272 Table 1. LODs, based on a signal-to-noise ratio of 3:1, were calculated using standard

273 solutions at low concentration levels (in the range 0.3-2.6 mg/L). The values obtained 274 are similar to those reported in the literature with CE methods when using UV-detection 275 (26,33). LOQs, based on a signal-to-noise ratio of $10: 1$, between 1.0 and $8.5 \mathrm{mg} / \mathrm{L}$ were 276 obtained. Calibration curves based on peak area at concentrations between 1 and 100 $277 \mathrm{mg} / \mathrm{L}$ (higher concentrations for some compounds) were established. Good linearity was 278 observed for all compounds with correlation coefficients $\left(\mathrm{r}^{2}\right)$ higher than 0.990.

279 Run-to-run and day-to-day precisions for compound quantification, at a 280 concentration level of $30 \mathrm{mg} / \mathrm{L}$ (using standard solutions), were calculated by external 281 calibration for the two CE instruments (P/ACE MDQ and P/ACE 5500). In order to 282 obtain the run-to-run precision, five replicate determinations were carried out. Similarly, 283 day-to-day precision was calculated by performing 15 replicate determinations on three 284 non-consecutive days (five replicates each day). To better validate the proposed method, 285 precision was evaluated using two different CE instruments. The RSDs obtained for 286 run-to-run and day-to-day precisions were similar using both $\mathrm{CE}$ instruments (in the 287 range $0.6-6.5 \%$ and $6.7-15.7 \%$, respectively). These results showed that the proposed 288 method was satisfactory in terms of precision for the quantitative analysis of 289 polyphenols and phenolic acids. Run-to-run precision was also evaluated using pseudo290 matrix matched calibration by performing five replicate determinations of a wine 291 sample matrix spiked at two concentration levels (10 and $30 \mathrm{mg} / \mathrm{L})$. RSD values in the 292 range $5.7-11.2 \%$ and $3.4-8.9 \%$ for concentration levels of $10 \mathrm{mg} / \mathrm{L}$ and $30 \mathrm{mg} / \mathrm{L}$ 293 respectively were obtained. Pseudo-matrix matched calibration showed better precision 294 as expected because it allows the correction of the baseline shift observed in the wine 295 electropherograms. Finally, Table 1 also shows that good run-to-run and day-to-day 296 precisions of migration times were also obtained, with RSD values lower than $3.4 \%$.

\section{Analysis of polyphenols in Spanish wines}

In order to evaluate the applicability of the proposed method to the determination of twenty polyphenols and phenolic acids in real samples, 49 commercial Spanish wines were analyzed. No sample treatment was applied and the wines were only filtered through $0.45 \mu \mathrm{m}$ nylon membranes before injection. Figure $3 \mathrm{a}$ shows, as an example, the electropherogram obtained for the analysis of a wine sample at three 
306 are much simpler than those of the wines due to the components of the sample matrix.

307 For this reason, prior to analyze all wine samples, three different quantitation methods

308 were evaluated: (i) external calibration using standards prepared in water, (ii) standard

309 addition, and (iii) pseudo-matrix matched external calibration (using a wine sample as

310 matrix). These three calibration methods were applied to the analysis of five selected

311 wines.

312 First, wine samples were analyzed using standard addition in order to establish

313 the concentration of polyphenols in each sample. All the analyses were performed by

314 triplicate, and the results are given in Table 2. Compound identification was based on

315 the concordance of retention time and UV absorption spectrum with those of the

316 standards. The same samples were then analyzed by external calibration using standards

317 prepared in Milli-Q water, and by pseudo-matrix matched calibration. As no wine free

318 of polyphenols can be found, for pseudo-matrix matched calibration two wines with low

319 concentration of polyphenols were used as sample matrices to prepare all the other

320 standards to be used in the calibration, and concentration of each standard was then

321 calculated taking into account the basal level in the native wine. These analyses were

322 also performed by triplicate with each quantitation method and the results are also given

323 in Table 2. In all cases pseudo-matrix matched calibration provided similar results to the

324 standard addition calibration. External calibration using standards prepared in Milli-Q

325 water seems to give also similar results, or slightly different, than those observed with

326 standard addition. Nevertheless, in order to see if there is any statistical difference

327 between these results, a statistical paired-sample comparison analysis was performed

328 with the results obtained either using external calibration or pseudo-matrix matched

329 calibration procedures with those established by standard addition. For a 95\%

330 confidence level, the results achieved with the three calibration procedures were not

331 significantly different, with $p$-values (Table 2) higher than 0.05 (probability at the

332 confidence level) in all cases. However, it must be mentioned that for some compounds

333 (such as t-cinnamic, syringic acid, and gallic acid) in some wines, statistical differences

334 between external calibration and standard addition were observed. In consequence, the

335 optimized CZE method, using pseudo-matrix matched calibration with standards

336 prepared in wine matrix, can be proposed as an economic and rapid method for the

337 analysis of polyphenols in wine samples, providing a good idea of polyphenol

338 concentration levels for wine characterization. 
Table 3 shows the concentration levels of polyphenols found in 12 of the 49 commercial Spanish wines analyzed, and the concentration range observed for each polyphenol, as well as the average concentration and the standard deviation, are also included. As shown in the table, a wide compositional variation was observed. Five polyphenols were found in all the analyzed samples: 2-(4-hydroxyphenyl)ethanol, resveratrol, quercitrin, caffeic acid and gallic acid. Coumaric acid, veratric acid, cinnamic acid, syringic acid, quercetin and 3,4-dihydroxybenzoic acid were also found in almost all wines analyzed. Gallic acid was usually found at relatively high concentrations, with values ranging from 9 to $209 \mathrm{mg} / \mathrm{L}$. 2-(4-hydroxyphenyl)ethanol was also found at relatively high concentrations in most of the samples (from 33 to 145 $\mathrm{mg} / \mathrm{L})$. The other polyphenols found in the analyzed samples presented, in general, concentration levels ranging from LOD to $\sim 50 \mathrm{mg} / \mathrm{L}$, although in some wines high concentration levels were observed for some specific polyphenols such as homovanillic acid in wines 22 and 23 (155 and $181 \mathrm{mg} / \mathrm{L}$, respectively), epicatechin in wine 49 (154 $\mathrm{mg} / \mathrm{L}$ ), or catechin in wines 22 and 24 (66 and $70 \mathrm{mg} / \mathrm{L}$, respectively). Only two of the twenty polyphenols analyzed (sinapic acid and homogentisic acid) were not detected in any sample. It should be pointed out that polyphenol levels found in this work for red wines are, in general, in agreement with those described in the literature for this kind of samples $(25,33)$. The wide compositional variation and number of polyphenols found in the analyzed wines show that the determination of a high number of polyphenols is necessary for a better wine characterization.

\section{Principal Component Analysis}

The developed CZE-UV method was also evaluated in order to see if either the electrophoretic profile or the polyphenol profile was useful for wine characterization in relation to the region of origin. For this purpose, a batch of 53 Spanish wines from three different regions (Catalunya, La Rioja and Castilla - La Mancha) were analyzed with the proposed CZE-UV (average concentrations for each polyphenol compound are presented in Table 4) and the results were treated by PCA.

Raw electrophoretic profiles were firstly evaluated as a source of analytical information for building characterization models. Since electropherograms showed certain degree of variability in the migration time of components the extraction of solid conclusions was hindered. This drawback was solved by peak alignment of 
373 (COW) written for MATLAB. Owing to the complexity of the electrophoretic profiles,

374 COW was inefficient to deal with peak shifting in the whole time range so the 375 correction was performed on three different time window subsets as follows: 0 to 11 $376 \mathrm{~min}, 11$ to $19 \mathrm{~min}$ and 19 to $25 \mathrm{~min}$. After COW application, electropherograms at each 377 wavelength were reconstituted and the resulting data sets were analyzed by PCA. 378 Exploratory results showed the predominance of Catalunya and Rioja wines in some 379 parts of the plot of scores although some of the samples appeared in the wrong positions. 380 Regarding Castilla - La Mancha region, samples lay in an intermediate zone and mixed 381 with the other classes.

382 Since the presence of irrelevant data in the set under study may hinder the 383 extraction of reliable conclusion regarding to origin, next step was focused on the 384 selection of discriminat features. In this case, peak areas of the most descriptive peaks 385 were taken as analytical data to be treated by PCA. In particular, the data set consisted 386 of 15 peak areas of known and unknown compounds extracted as follows: 2 peaks at $387280 \mathrm{~nm}, 6$ peaks at $310 \mathrm{~nm}$ and 7 peaks at $370 \mathrm{~nm}$ (see Fig. 3a). PCA results showed 388 that PC1 was mainly focused on the description of the peak intensities and variance 389 dealing with geographical characteristics was not retained. Information of the origin of 390 wines was captured by PC2 and PC3. The scatter plot of scores of PC2 versus PC3 (Fig.

$3913 b)$ suggested that wines from Catalunya were located on the right part while Rioja 392 wines appeared on the top and central-left side. Castilla - La Mancha wines were mainly 393 on the left side and they seemed to be less distinguishable from the other classes. The 394 distribution of variables with respect to PC2 and PC3 showed that samples with higher 395 contents of compounds S1, S3, S4 and S6 were typical of Catalunya. Species S9, S14 396 and S15 were quite characteristic of Rioja, and compounds S5, S11 and S12 were more 397 abundant in Castilla - La Mancha wines. Some of these peaks have not been identified 398 yet. For the known components, tirosol, gallic acid were more characteristic of 399 Catalunya, p-coumaric and caffeic acids were encountered at higher levels in Rioja 400 samples and protocatechuic was more specific of Castilla - La Mancha wines.

The results obtained in this study show that the developed CZE method, using 403 pseudo-matrix matched calibration with standards prepared in wine matrix, can be 404 proposed as a rapid and economic method for the determination of polyphenols in wine 405 samples. The method was applied to analyze these compounds in 49 commercial 406 Spanish wines from different regions. Eighteen of the twenty polyphenols studied were 
407 detected and, in most of the samples, quantified, being gallic acid and 2-(4-

408 hydroxyphenyl)ethanol the compounds found at higher concentrations. The peak areas

409 of the most abundant compounds (some of them identified by comparison with

410 standards and some of them unknown) resulted in an excellent source of information to

411 carry out the wine characterization. Results from PCA proved that such compositional

412 data allowed wines to be clustered according to their origins. Besides, the most

413 discriminant analytes representative of each geographical area were identified.

414

415 ACKNOWLEDGEMENTS

416

417 The authors gratefully acknowledge financial support from the Spanish Ministerio de

418 Ciencia y Tecnologia under the project CTQ 2008-04776/BQU.

419 
(1) Nurk, E.; Refsum, H.; Drevon, C.A.; Tell, H.A.; Nygaard, K.; Engedal, A.D.; Smith, A.D. Intake of flavonoid-rich wine, tea, and chocolate by eldery men and women is associated with better cognitive test performance. J. Nutr. 2009, 139, 120-127.

426

427

428

429

430

431

432

433

434

435

436

437

438

439

440

441

442

443

444

445

446

447

448

449

450

451

452

453

454

455

456

457

458

459
(2) Udenigwe, C.C.; Ramprasath, V.R.; Aluko, R.E.; Jones, P.J.H. Potential of resveratrol in anticancer and anti-inflammatory therapy. Nutr. Rev. 2008, 66, 445-454.

(3) Preys, S.; Mazerolles, G.; Courcoux, P.; Samson, A.; Fischer, U.; Hanafi, M.; Bertrand, D.; Cheynier, V. Relationshipbetween polyphenolic composition and some sensory properties in red wines using multiway analyses. Anal. Chim. Acta 2006, 563, 126-136.

(4) Viñas, P.; López-Erroz, C.; Marín-Hernández, J.J.; Hernández-Córdoba, M. Determination of phenols in wine my liquid chromatography with photodiode array and fluorescence detection. J. Chromatogr. A 2000, 871, 85-93.

(5) Kerem, Z.; Bravdo, B.-A.; Shoseyov, O.; Tugendhaft, Y. Rapid liquid chromatography-ultraviolet determination of organic acids and phenolic compounds in red wine and must. J. Chromatogr. A 2004, 1052, 211-215.

(6) Tarola, A.M.; Milano, F.; Giannetti, V. Simultaneous determination of phenolic compounds in red wines by HPLC-UV. Anal. Lett. 2007, 40, 2433-2445.

(7) Rodriguez-Bernaldo de Quiros, A.; Lage-Yusty, M.A.; Lopez-Hernandez, J. Comparison of two stationary phases for the separation of five selected polyphenols. Talanta 2008, 77, 98-102.

(8) Rastija, V.; Srecnik, G.; Marica, M.S. Polyphenolic composition of Croatian wines with different geographical origins. Food Chem. 2009, 115, 54-60.

(9) Dugo, P.; Cacciola, F.; Donato, P.; Airado-Rodriguez, D.; Herrero, M.; Mondello, L. Comprehensive two-dimensional liquid chromatography to quantify polyphenols in red wines. J. Chromatogr. A 2009, 1216, 7483-7487.

(10) Pereira, V.; Caamara, J.S.; Cacho, J.; Marques, J.C. HPLC-DAD methodology for the quantification of organic acids, furans and polyphenols by direct injection of wine samples. J. Sep. Sci. 2010, 33, 1204-1215.

(11) Paixao, N.; Pereira, V.; Marques, J.C.; Camara, J.S. Quantification of polyphenols with potential antioxidant properties in wines using reverse phase HPLC. J. Sep. Sci. 2008, 31, 2189-2198.

(12) Kartsova, L.A.; Alekseeva, A.V. Chromatographic and electrophoretic methods for determining polyphenol compounds. J. Anal. Chem. 2008, 63, 1024-1033.

(13) Jaitz, L.; Siegl, K.; Eder, R.; Rak, G.; Abranko, L.; Koellnsperger, G.; Hann, S. LC-MS/MS analysis of phenols for classification of red wine according to geographic origin, grape variety and vintage. Food Chem. 2010, 122, 366-372. 
460

461

462

463

464

465

466

467

468

469

470

471

472

473

474

475

476

477

478

479

480

481

482

483

484

485

486

487

488

489

490

491

492

493

494

495

496

497

(14) Vanhoenacker, G.; De Villiers, A.; Lazou, K.; De Keukeleire, D.; Sandra, P. Comparison of high-performance liquid chromatography - mass spectroscopy and capillary electrophoresis - mass spectroscopy for the analysis of phenolic compounds in diethyl ether extracts of red wines. Chromatographia 2001, 54, 309-315.

(15) Viñas, P.; Campillo, N.; Martinez-Castillo, N.; Hernandez-Cordoba, M. Solidphase microextraction on-fiber derivatization for the analysis of some polyphenols in wine and grapes using gas chromatography-mass spectrometry. $J$. Chromatogr. A 2009, 1216, 1279-1284.

(16) Fernandes, C.I.S.; Rebelo, M.J.F. Polyphenolic biosensors - application in red wines. Portugaliae Electrochim. Acta 2009, 27, 457-462.

(17) Photinon, K.; Chalermchart, Y.; Khanongnuch, C.; Wang, S.-H.; Liu, C.-C. A thik-film sensor as novel device for determination of polyphenols an their antioxidant capacity in white wine. Sensors 2010, 10, 1670-1678.

(18) Makhotkina, O.; Kilmartin, P.A. The use of cyclic voltammetry for wine analysis: Determination of polyphenols and free sulfur dioxide. Anal. Chim. Acta 2010, 668, 155-165.

(19) Sádecká, J.; Polonský, J. Electrophoretic methods in the analysis of beverages. $J$. Chromatogr. A 2000, 880, 243-279.

(20) Cifuentes, A. Recent advances in the application of capillary electromigration methods for food analysis. Electrophoresis 2006, 27, 283-303.

(21) García-Cañas, V.; Cifuentes, A. Recent advances in the application of capillary electromigration methods in food analysis. Electrophoresis 2008, 29, 294-309.

(22) Gu, X.; Chu, Q.; O'Dwyer, M.; Zeece, M. Analysis of resveratrol in wine by capillary zone electrophoresis. J. Chromatogr. A 2000, 881, 471-481.

(23) Demianova, Z.; Siren, H.; Kuldvee, R.; Riekkola, M.1. Nonaqueous capillary electrophoretic separation of polyphenolic compounds in wine using coated capillaries at high pH in methanol. Electrophoresis 2003, 24, 4264-4271.

(24) Hamoudová, R.; Urbánek, M.; Pospisilová, M.; Polásek, M. Assay of phenolic compounds in red wine by on-line combination of capillary isotachophoresis and capillary zone electrophoresis. J. Chromatogr. A 2004, 1032, 281-287.

(25) Pazourek, J.; Gonzalez, G.; Revilla, A.L.; Havel, J. Separation of polyphenols in Canary Islands wine by capillary zone electrophoresis without preconcentration. J. Chromatogr. A 2000, 874, 111-119.

(26) Arce, L.; Teresa Tena, M.; Rios, A.; Valcarcel, M. Determination of transresveratrol and other polyphenols in wines by a continuous flow sample cleanup system followed by a capillary electrophoresis separation. Anal. Chim. Acta 1998, 359, 27-38. 
(27) Minussi, R.C.; Rossi, M.; Bologna, L.; Cordi, L.; Rotilio, D.; Pastore, G.M.; Durán, N. Phenolic compounds and total antioxidant potential of commercial wines. Food Chem. 2003, 82, 409-416.

(28) Andrade, P.B.; Oliveira, B.M.; Seabra, R.M.; Ferreira, M.A.; Ferreres, F.; García-Viguera, C. Analysis of phenolic compounds in Spanish Albariño and Portuguese Alvarinho and Loureiro wines by capillary zone electrophoresis and high-performance liquid chromatography. Electrophoresis 2001, 22, 1568-1572.

(29) Peng, Y.; Chu, Q.; Liu, F.; Ye, J. Determination of phenolic constituents of biological interest in red wine by capillary-electrophoresis with electrochemical detection. J. Agric. Food Chem. 2004, 52, 153-156.

(30) García-Viguera, C.; Bridle, P. Analysis of non-coloured phenolic compounds in red wines. A comparison of high-performance liquid chromatography and capillary zone electrophoresis. Food Chem. 1995, 54, 349-352.

(31) Wang, S.P.; Huang, K.J. Determination of flavonoids by high-performance liquid chromatography amd capillary electrophoresis. J. Chromatogr. A 2004, 1032, 273-279.

(32) Rodríguez-Delgado, M.A.; Pérez, M.L.; Corbella, R.; González, G.; Montelongo, F.J.G. Optimization of the separation of phenolic compounds by micellar electrokinetic capillary chromatography. J. Chromatogr. A 2000, 871, 427-438.

(33) Peres, R.G.; Micke, G.A.; Tavares, M.F.M.; Rodriguez-Amaya, D.B. Multivariant optimization, validation, and application of capillary electrophoresis for simultaneous determination of polyphenols and phenolic acids in Brazilian wines. J. Sep. Sci. 2009, 32, 3822-3828.

(34) Sun, Y.; Fang, N.; Chen, D.D.Y.; Donkor, K.K. Determination of potentially anti-carcirogenic flavonoids in wines by micellar electrokinetic chromatography. Food Chem. 2008, 106, 415-420.

(35) Spanilá, M.; Pazourek, J.; Farková, M.; Havel, J. Optimization of solid-phase extraction using artificial neural networks in combination with experimental design for determination of resveratrol by capillary zone electrophoresis in wine. J. Chromatogr. A 2005, 1084, 180-185.

(36) Dobiásová, Z.; Pazourek, J.; Havel, J. Simultaneous determination of transresveratrol and sorbic acid in wine by capillary zone electrophoresis. Electrophoresis 2002, 23, 263-267.

(37) Chu, Q.; O'Dwyer, M.; Zeece, M. Direct analysis of Resveratrol in wine by micellar electrokinetic capillary electrophoresis. J. Agric. Food Chem. 1998, 46, 509-513.

(38) Saurina, J. Characterization of wines using compositional profiles and chemometrics. TrAC, Trends Anal. Chem. 2010, 29, 234-245.

(39) Wise, B.; Gallager, N.B. PLS_Toolbox for use with MATLAB, version 2.0; Eigenvector Research Inc.; Mason, WA, 1992. 
538 (40) Massart, D.L.; Vandeginste, B.G.M.; Buydens, L.M.C.; de Jong, S.; Lewi, P.J.; Smeyers-Verbeke, J. Handbook of Chemometrics and Qualimetrics; Elsevier: Amsterdam, 1997.

541

542

543 
547 Figure 1. Simultaneous optimization of isopropanol percentage and borate buffer

548 concentration from a $5 \times 3$ grid design. (a) Number of peaks separated; (b) Resolution

549 between $p$-coumaric and quercetin peaks; (c) Run time; (d) Overall desirability.

550

551 Figure 2. Electrophoretic separation of an aqueous standard mixture of 20 polyphenols.

552 BGE: $30 \mathrm{mM}$ tetraborate buffer with 5\% isopropanol. Capillary voltage: $+25 \mathrm{kV}$, 553 pressure assisted separation $(3.5 \mathrm{kPa})$ from minute 18 . Acquisition wavelength: $280 \mathrm{~nm}$. 554 Peak identification: see Table 1.

556 Figure 3. (a) Electropherograms of a wines sample recorded at 280, 310 and $370 \mathrm{~nm}$. (b)

557 PCA results (score and loading plots) using selected peak areas as analytical data.

558

559

560

561

562

563

564

565

566

567

568

569

570

571

572

573

574

575

576

577

578

579

580

581

582

583

584

585

586 


\section{Table 1. Instrumental quality parameters}

\begin{tabular}{|c|c|c|c|c|c|c|c|c|c|c|c|c|c|}
\hline \multirow[t]{3}{*}{$\mathbf{N}^{\mathbf{o}}$} & \multirow[t]{3}{*}{ Compound } & \multirow{3}{*}{$\begin{array}{l}\text { LOD } \\
(\mathrm{mg} / \mathrm{L})\end{array}$} & \multirow{3}{*}{$\begin{array}{l}\text { LOQ } \\
(\mathrm{mg} / \mathrm{L})\end{array}$} & \multirow{3}{*}{$\begin{array}{l}\text { Working range } \\
(\mathrm{mg} / \mathrm{L})\end{array}$} & \multirow[t]{3}{*}{ Linearity } & \multicolumn{4}{|c|}{ run-to-run precision ( $\%$ RSD, $n=5$ ) } & \multicolumn{4}{|c|}{ day-to-day precision $(\% \mathrm{RSD}, \mathrm{n}=3 \times 5)$} \\
\hline & & & & & & \multicolumn{2}{|c|}{ migration time } & \multicolumn{2}{|c|}{ Concentration $^{\mathrm{a}}$} & \multicolumn{2}{|c|}{ migration time } & \multicolumn{2}{|c|}{ Concentration $^{a}$} \\
\hline & & & & & & $\begin{array}{l}\text { MDQ } \\
\text { CE }\end{array}$ & $\begin{array}{l}\mathbf{5 5 0 0} \\
\mathbf{C E}\end{array}$ & $\begin{array}{l}\text { MDQ } \\
\text { CE }\end{array}$ & $\begin{array}{l}\mathbf{5 5 0 0} \\
\mathbf{C E}\end{array}$ & $\begin{array}{l}\text { MDQ } \\
\text { CE }\end{array}$ & $\begin{array}{l}\mathbf{5 5 0 0} \\
\mathbf{C E}\end{array}$ & $\begin{array}{l}\text { MDQ } \\
\text { CE }\end{array}$ & $\begin{array}{l}\mathbf{5 5 0 0} \\
\mathbf{C E}\end{array}$ \\
\hline 1 & 2-(4-Hydroxyphenyl)ethanol & 0.5 & 1.7 & $2-200$ & $>0.990$ & 0.1 & 0.3 & 2.1 & 4.5 & 0.8 & 1.6 & 9.5 & 11.0 \\
\hline 2 & Resveratrol & 1.6 & 5.1 & $5-200$ & $>0.992$ & 0.3 & 0.1 & 0.6 & 1.7 & 1.2 & 1.3 & 6.7 & 6.7 \\
\hline 3 & (-)-Epicatechin & 2.4 & 8.0 & $8-100$ & $>0.990$ & 0.6 & 0.5 & 1.2 & 2.3 & 0.6 & 0.8 & 8.5 & 9.2 \\
\hline 4 & $(+)$-Catechin & 2.5 & 8.1 & $8-100$ & $>0.996$ & 0.3 & 0.4 & 1.5 & 2.8 & 0.7 & 1.2 & 7.8 & 8.9 \\
\hline 5 & Veratric acid & 0.3 & 1.0 & $1-100$ & $>0.997$ & 0.2 & 0.4 & 2.9 & 4.2 & 0.8 & 1.8 & 12.3 & 11.5 \\
\hline 6 & Homovanillic acid & 0.3 & 1.1 & $1-200$ & $>0.998$ & 0.3 & 0.2 & 1.4 & 2.1 & 0.6 & 1.9 & 11.4 & 10.7 \\
\hline 7 & Vanillin & 0.7 & 2.4 & $2-100$ & $>0.999$ & 0.1 & 0.3 & 2.3 & 6.5 & 1.9 & 2.2 & 10.1 & 10.3 \\
\hline 8 & t-Cinnamic acid & 0.4 & 1.4 & $1-100$ & $>0.998$ & 0.3 & 0.4 & 3.1 & 2.1 & 0.7 & 2.2 & 15.7 & 13.7 \\
\hline 9 & Sinapic acid & 0.9 & 3.1 & $3-100$ & $>0.996$ & 0.2 & 0.3 & 2.9 & 1.5 & 0.5 & 2.3 & 11.6 & 10.6 \\
\hline 10 & Quercitrin & 0.9 & 2.8 & $3-100$ & $>0.990$ & 0.3 & 0.3 & 2.5 & 1.3 & 0.4 & 2.5 & 14.6 & 11.8 \\
\hline 11 & Homogentistic acid & 0.9 & 2.8 & $3-100$ & $>0.998$ & 0.4 & 0.4 & 3.9 & 2.1 & 0.7 & 2.7 & 13.8 & 10.5 \\
\hline 12 & Syringic acid & 0.6 & 1.9 & $2-100$ & $>0.996$ & 0.2 & 0.6 & 4.4 & 2.8 & 1.5 & 3.4 & 11.6 & 11.3 \\
\hline 13 & Ferulic acid & 0.5 & 1.8 & $2-100$ & $>0.998$ & 0.2 & 0.1 & 3.6 & 1.8 & 1.5 & 2.3 & 13.3 & 13.9 \\
\hline 14 & Fisetin & 0.7 & 2.2 & $2-100$ & $>0.999$ & 0.6 & 0.1 & 2.7 & 5.8 & 0.9 & 1.0 & 14.8 & 10.9 \\
\hline 15 & p-Coumaric acid & 0.7 & 2.3 & $2-100$ & $>0.999$ & 0.04 & 0.1 & 1.6 & 3.4 & 1.4 & 0.8 & 14.1 & 12.7 \\
\hline 16 & Quercetin & 2.6 & 8.5 & $8-100$ & $>0.998$ & 0.2 & 0.2 & 1.4 & 2.4 & 0.7 & 1.0 & 10.2 & 10.6 \\
\hline 17 & 4-Hydroxybenzoic acid & 0.4 & 1.4 & $1-100$ & $>0.999$ & 0.1 & 0.1 & 1.9 & 2.5 & 1.3 & 0.8 & 9.9 & 9.8 \\
\hline 18 & Caffeic acid & 0.5 & 1.7 & $2-100$ & $>0.998$ & 0.2 & 0.2 & 2.8 & 4.7 & 2.1 & 0.9 & 11.7 & 10.6 \\
\hline 19 & Gallic acid & 2.1 & 6.9 & $7-250$ & $>0.998$ & 0.2 & 0.1 & 2.5 & 4.0 & 2.1 & 0.9 & 12.7 & 11.1 \\
\hline 20 & 3,4-Dihydroxybenzoic acid & 0.6 & 2.1 & $2-100$ & $>0.998$ & 0.2 & 0.2 & 5.0 & 4.2 & 2.2 & 1.8 & 10.7 & 11.6 \\
\hline
\end{tabular}

${ }^{a}$ Concentration: $30 \mathrm{mg} / \mathrm{L}$. Quantitation performed by external calibration. 
Table 2: Comparison of calibration procedures for polyphenol quantitation in Spanish wines by the proposed CZE method.

\begin{tabular}{|c|c|c|c|c|c|c|c|c|c|c|c|c|c|c|c|c|}
\hline \multirow[t]{2}{*}{$\mathbf{N}^{\circ}$} & \multirow[t]{2}{*}{ Compound } & \multicolumn{3}{|l|}{ Wine 1} & \multicolumn{3}{|l|}{ Wine 2} & \multicolumn{3}{|l|}{ Wine 3} & \multicolumn{3}{|l|}{ Wine 4} & \multicolumn{3}{|l|}{ Wine 5} \\
\hline & & EC & SA & pMM & EC & SA & pMM & EC & SA & pMM & EC & SA & pMM & EC & SA & pMM \\
\hline 1 & 2-(4-Hydroxyphenyl)ethanol & $60.2 \pm 5.0$ & $56.3 \pm 2.0$ & $58.9 \pm 4.0$ & $89.7 \pm 6.5$ & $75.9 \pm 4.3$ & $80.3 \pm 6.1$ & $115.1 \pm 14.9$ & $98.71 \pm 9.9$ & $109.0 \pm 9.9$ & $85.1 \pm 6.3$ & $86.3 \pm 4.3$ & $84.1 \pm 2.9$ & $\sim \mathrm{LOD}$ & $\sim \mathrm{LOD}$ & $\sim \mathrm{LOD}$ \\
\hline 2 & Resveratrol & $\sim \mathrm{LOD}$ & $\sim$ LOD & $\sim \mathrm{LOD}$ & $\sim$ LOD & $\sim$ LOD & $\sim$ LOD & $\sim$ LOD & $\sim$ LOD & $\sim \mathrm{LOD}$ & $\sim \mathrm{LOD}$ & $\sim$ LOD & $\sim \mathrm{LOD}$ & $\sim \mathrm{LOD}$ & $\sim \mathrm{LOD}$ & $\sim \mathrm{LOD}$ \\
\hline 3 & $(-)$-Epicatechin & $\sim$ LOD & $\sim$ LOD & $\sim$ LOD & $\sim$ LOD & $\sim$ LOD & $\sim$ LOD & $\sim$ LOD & $\sim$ LOD & $\sim$ LOD & $\sim$ LOD & $\sim$ LOD & $\sim$ LOD & $\sim$ LOD & $\sim$ LOD & $\sim$ LOD \\
\hline 4 & $(+)$-Catechin & $\sim \mathrm{LOD}$ & $\sim \mathrm{LOD}$ & $\sim \mathrm{LOD}$ & $\sim \mathrm{LOD}$ & $\sim \mathrm{LOD}$ & $\sim \mathrm{LOD}$ & $\sim$ LOD & $\sim \mathrm{LOD}$ & $\sim \mathrm{LOD}$ & $\sim \mathrm{LOD}$ & $\sim \mathrm{LOD}$ & $\sim \mathrm{LOD}$ & $\sim \mathrm{LOD}$ & $\sim \mathrm{LOD}$ & $\sim \mathrm{LOD}$ \\
\hline 5 & Veratric acid & n.d. & n.d. & n.d. & n.d. & n.d. & n.d. & n.d. & n.d. & n.d. & n.d. & n.d. & n.d. & n.d. & n.d. & n.d. \\
\hline 6 & Homovanillic acid & n.d. & n.d. & n.d. & n.d. & n.d. & n.d. & n.d. & n.d. & n.d. & n.d. & n.d. & n.d. & n.d. & n.d. & n.d. \\
\hline 7 & Vanillin & $\sim$ LOD & $\sim$ LOD & $\sim$ LOD & $\sim$ LOD & $\sim$ LOD & $\sim$ LOD & n.d. & n.d. & n.d. & $\sim \mathrm{LOD}$ & $\sim$ LOD & $\sim$ LOD & n.d. & n.d. & n.d. \\
\hline 8 & $\mathrm{t}$-Cinnamic acid & $5.2 \pm 0.1$ & $1.0 \pm 0.1$ & $1.2 \pm 0.1$ & $5.1 \pm 0.2$ & $1.5 \pm 0.3$ & $2.1 \pm 0.3$ & $6.5 \pm 0.1$ & $2.5 \pm 0.2$ & $2.0 \pm 0.2$ & $\sim$ LOD & $\sim$ LOD & $\sim$ LOD & $6.1 \pm 0.4$ & $2.3 \pm 0.5$ & $3.4 \pm 0.5$ \\
\hline 9 & Sinapic acid & n.d. & n.d. & n.d. & n.d. & n.d. & n.d. & n.d. & n.d. & n.d. & n.d. & n.d. & n.d. & n.d. & n.d. & n.d. \\
\hline 10 & Quercitrin & $20.5 \pm 0.4$ & $23.6 \pm 1.3$ & $20.4 \pm 0.7$ & $12.9 \pm 0.1$ & $10.6 \pm 0.1$ & $11.9 \pm 0.1$ & $34.5 \pm 2.5$ & $25.6 \pm 0.8$ & $30.2 \pm 0.9$ & $21.7 \pm 1.7$ & $28.5 \pm 5.6$ & $27.0 \pm 2.4$ & $15.9 \pm 2.0$ & $20.7 \pm 3.0$ & $19.0 \pm 2.3$ \\
\hline 11 & Homogentistic acid & n.d. & n.d. & n.d. & n.d. & n.d. & n.d. & n.d. & n.d. & n.d. & n.d. & n.d. & n.d. & n.d. & n.d. & n.d. \\
\hline 12 & Syringic acid & $7.6 \pm 0.8$ & $3.2 \pm 1.0$ & $4.0 \pm 1.0$ & $\sim \mathrm{LOD}$ & $\sim$ LOD & $\sim \mathrm{LOD}$ & $4.7 \pm 0.4$ & $3.1 \pm 0.4$ & $2.2 \pm 0.4$ & $12.7 \pm 2.0$ & $8.0 \pm 4.7$ & $9.1 \pm 5.0$ & $19.2 \pm 0.9$ & $9.6 \pm 1.6$ & $10.2 \pm 1.3$ \\
\hline 13 & Ferulic acid & $\sim \mathrm{LOD}$ & $\sim$ LOD & $\sim \mathrm{LOD}$ & $16.3 \pm 1.9$ & $6.8 \pm 0.7$ & $7.5 \pm 0.5$ & n.d. & n.d. & n.d. & n.d. & n.d. & n.d. & $\sim$ LOD & $\sim \mathrm{LOD}$ & $\sim \mathrm{LOD}$ \\
\hline 14 & Fisetin & $\sim$ LOD & $\sim$ LOD & $\sim$ LOD & $\sim$ LOD & $\sim$ LOD & $\sim$ LOD & n.d. & n.d. & n.d. & n.d. & n.d. & n.d. & n.d. & n.d. & n.d. \\
\hline 15 & p-Coumaric acid & n.d. & n.d. & n.d. & $4.8 \pm 0.7$ & $3.3 \pm 1.5$ & $6.7 \pm 1.5$ & $\sim$ LOD & $\sim$ LOD & $\sim$ LOD & $\sim$ LOD & $\sim$ LOD & $\sim$ LOD & $2.5 \pm 0.3$ & $5.1 \pm 0.8$ & $4.9 \pm 0.7$ \\
\hline 16 & Quercetin & $\sim$ LOD & $\sim$ LOD & $\sim$ LOD & $\sim$ LOD & $\sim$ LOD & $\sim$ LOD & $\sim$ LOD & $\sim$ LOD & $\sim$ LOD & n.d. & n.d. & n.d. & $11.8 \pm 0.8$ & $5.1 \pm 0.5$ & $3.9 \pm 0.5$ \\
\hline 17 & 4-hydroxybenzoic acid & n.d. & n.d. & n.d. & n.d. & n.d. & n.d. & n.d. & n.d. & n.d. & n.d. & n.d. & n.d. & n.d. & n.d. & n.d. \\
\hline 18 & Caffeic acid & $\sim \mathrm{LOD}$ & $\sim$ LOD & $\sim$ LOD & $9.0 \pm 1.2$ & $8.0 \pm 1.9$ & $8.9 \pm 1.7$ & $2.2 \pm 0.3$ & $3.8 \pm 1.0$ & $3.9 \pm 0.9$ & $5.3 \pm 0.8$ & $6.6 \pm 1.2$ & $6.6 \pm 1.1$ & $8.4 \pm 0.7$ & $9.1 \pm 0.7$ & $12.7 \pm 0.5$ \\
\hline 19 & Gallic acid & $43.1 \pm 1.9$ & $82.3 \pm 19.5$ & $91.0 \pm 4.6$ & $71.0 \pm 4.2$ & $51.6 \pm 4.5$ & $63.1 \pm 5.2$ & $100.7 \pm 5.4$ & $87.6 \pm 1.2$ & $80.5 \pm 1.0$ & $45.5 \pm 3.6$ & $77.0 \pm 23.7$ & $58.4 \pm 4.3$ & $35.2 \pm 4.2$ & $43.5 \pm 16.7$ & $43.8 \pm 5.0$ \\
\hline 20 & 3,4-Dihydroxybenzoic acid & $\sim$ LOD & $\sim \mathrm{LOD}$ & $\sim$ LOD & $\sim$ LOD & $\sim$ LOD & $\sim$ LOD & n.d. & n.d. & n.d. & $\sim \mathrm{LOD}$ & $\sim$ LOD & $\sim \mathrm{LOD}$ & $\sim \mathrm{LOD}$ & $\sim$ LOD & $\sim \mathrm{LOD}$ \\
\hline & $p$.values ${ }^{\mathrm{a}}$ & 0.48 & - & 0.46 & 0.09 & - & 0.11 & 0.12 & - & 0.70 & 0.35 & - & 0.38 & 0.84 & - & 0.61 \\
\hline
\end{tabular}

All concentrations are in $\mathrm{mg} / \mathrm{L}$. Quantitations performed by triplicate $(\mathrm{n}=3)$, results expressed as: Concentration mean of samples analyzed \pm standard deviation

EC: External calibration; SA: Standard addition; pMM: pseudo-matrix matched calibration

n.d.: not detected

${ }^{\text {a }}$ for a $95 \%$ confidence level 
Table 3: Polyphenol concentration levels $(\mathrm{mg} / \mathrm{L})$ in Spanish wines obtained by the proposed CZE method.

\begin{tabular}{|c|c|c|c|c|c|c|c|c|c|c|c|c|c|c|c|}
\hline $\mathrm{N}^{\mathrm{o}}$ & Compound & Wine 6 & Wine 10 & Wine 16 & Wine 18 & Wine 20 & Wine 25 & Wine 36 & Wine 38 & Wine 40 & Wine 45 & Wine 47 & Wine 49 & $\begin{array}{l}\text { Concentration } \\
\text { range }\end{array}$ & average \pm st.dev \\
\hline 1 & 2-(4-Hydroxyphenyl)etanol & $99.4 \pm 9.7$ & $125.8 \pm 17.5$ & $59.7 \pm 2.0$ & $63.4 \pm 0.8$ & $77.23 \pm 2.1$ & $45.8 \pm 1.2$ & $61.1 \pm 0.5$ & $70.0 \pm 2.6$ & $68.1 \pm 1.4$ & $54.2 \pm 8.0$ & $145.9 \pm 4.9$ & $65.2 \pm 2.5$ & $0.3-145.9$ & $71.34 \pm 22.59$ \\
\hline 2 & Resveratrol & $9.4 \pm 0.6$ & $\sim$ LOD & $22.5 \pm 0.2$ & $\sim$ LOD & $23.9 \pm 0.1$ & $24.1 \pm 0.1$ & $25.6 \pm 0.05$ & $25.6 \pm 0.2$ & $28.0 \pm 0.1$ & $21.2 \pm 0.2$ & $20.9 \pm 0.01$ & $20.7 \pm 0.1$ & $0.8-28$ & $18.00 \pm 9.78$ \\
\hline 3 & Epicatechin & $\sim$ LOD & $\sim$ LOD & $16.9 \pm 1.7$ & n.d. & $12.9 \pm 2.3$ & $13.9 \pm 2.0$ & $52.6 \pm 17.6$ & $50.3 \pm 4.8$ & $15.4 \pm 1.2$ & n.d & $5.1 \pm 0.1$ & $2.2 \pm 0.04$ & $1.2-154.1$ & $24.34 \pm 31.93$ \\
\hline 4 & Catechin & $\sim \mathrm{LOD}$ & $\sim$ LOD & $0.7 \pm 0.1$ & n.d. & $0.8 \pm 0.05$ & $0.6 \pm 0.05$ & n.d. & $4.0 \pm 0.6$ & n.d. & $11.2 \pm 1.1$ & n.d. & $1.2 \pm 0.5$ & $0.6-86.5$ & $7.99 \pm 19.68$ \\
\hline 5 & Veratric acid & $7.14 \pm 0.8$ & $10.7 \pm 1.3$ & $35.6 \pm 0.1$ & $9 . .5 \pm 0.0$ & $39.9 \pm 6.0$ & $31.0 \pm 2.9$ & $19.3 \pm 1.6$ & n.d. & $23.4 \pm 0.7$ & $2.0 \pm 0.05$ & $6.9 \pm 0.1$ & $19.6 \pm 2.3$ & $2-40.6$ & $17.49 \pm 11.26$ \\
\hline 6 & Homovanillic acid & n.d. & n.d. & n.d. & n.d. & n.d. & $21.6 \pm 3.3$ & n.d. & n.d. & $3.6 \pm 0.4$ & n.d & n.d & n.d & $2.24-181$ & $49.17 \pm 68.27$ \\
\hline 7 & Vanillin & n.d. & n.d. & n.d. & n.d. & n.d. & $11.0 \pm 1.1$ & $16.6 \pm 2.1$ & $17.6 \pm 0.8$ & $5.8 \pm 0.4$ & n.d & $6.8 \pm 0.8$ & n.d & $0.35-21.1$ & $8.39 \pm 6.48$ \\
\hline 8 & t-Cinnamic acid & n.d. & $2.1 \pm 0.1$ & $10.3 \pm 0.1$ & n.d. & n.d. & $7.7 \pm 0.1$ & $12.6 \pm 1.0$ & $12.9 \pm 0.4$ & $2.1 \pm 0.1$ & $4.3 \pm 0.4$ & $6.1 \pm 0.1$ & $6.2 \pm 0.02$ & $0.2-19.7$ & $5.98 \pm 4.21$ \\
\hline 9 & Sinapic acid & n.d. & n.d. & n.d. & n.d. & n.d. & n.d. & n.d. & n.d. & n.d. & n.d. & n.d. & n.d. & n.d. & - \\
\hline 10 & Quercitrin & $13.0 \pm 2.6$ & $3.6 \pm 0.5$ & $7.0 \pm 1.4$ & $3.5 \pm 0.6$ & $13.8 \pm 1.3$ & $12.8 \pm 0.1$ & $4.9 \pm 0.9$ & $11.9 \pm 1.0$ & $24.1 \pm 0.7$ & $2.6 \pm 0.2$ & $8.3 \pm 0.9$ & $7.5 \pm 0.3$ & $1.4-31.9$ & $12.90 \pm 7.77$ \\
\hline 11 & Homogentisic acid & n.d. & n.d. & n.d. & n.d. & n.d. & n.d. & n.d. & n.d. & n.d. & n.d. & n.d. & n.d. & n.d. & - \\
\hline 12 & Syringic acid & $\sim \mathrm{LOD}$ & $3.9 \pm 0.5$ & $5.7 \pm 0.2$ & $7.9 \pm 0.4$ & n.d. & $3.4 \pm 0.5$ & $6.9 \pm 0.3$ & $9.3 \pm 0.07$ & $1.7 \pm 0.3$ & $3.6 \pm 0.4$ & $4.6 \pm 0.7$ & $5.3 \pm 0.4$ & $0.3-15.5$ & $4.94 \pm 3.19$ \\
\hline 13 & Ferulic acid & $\sim$ LOD & $\sim$ LOD & n.d. & $10.0 \pm 0.4$ & $9.9 \pm 0.02$ & $9.7 \pm 0.05$ & $12.7 \pm 0.6$ & $11.6 \pm 0.6$ & $7.5 \pm 0.2$ & n.d & $5.4 \pm 0.7$ & n.d & $0.25-15.5$ & $8.69 \pm 4.04$ \\
\hline 14 & Fisetin & $6.1 \pm 0.7$ & $10.6 \pm 1.6$ & n.d. & $15.0 \pm 0.3$ & n.d. & n.d & $18.5 \pm 1.3$ & $17.4 \pm 0.5$ & $7.5 \pm 1.2$ & $11.6 \pm 2.0$ & n.d. & n.d & $0.35-18.5$ & $10.40 \pm 5.17$ \\
\hline 15 & p-Coumaric acid & $1.35 \pm 0.01$ & $7.9 \pm 1.2$ & $16.1 \pm 0.6$ & $19.0 \pm 0.5$ & $11.7 \pm 0.5$ & $8.6 \pm 0.5$ & $15.0 \pm 0.3$ & $14.4 \pm 0.02$ & $6.4 \pm 0.3$ & $2.3 \pm 0.4$ & $9.1 \pm 0.6$ & $11.0 \pm 0.3$ & $0.35-19$ & $9.37 \pm 5.42$ \\
\hline 16 & Quercetin & $\sim$ LOD & $\sim$ LOD & $30.7 \pm 0.1$ & $32.6 \pm 1.2$ & $8.5 \pm 0.06$ & $30.4 \pm 1.0$ & $34.2 \pm 0.6$ & $33.9 \pm 0.02$ & $33.3 \pm 0.9$ & $28.6 \pm 0.4$ & $1.6 \pm 0.2$ & $1.7 \pm 0.3$ & $0.3-34.7$ & $18.88 \pm 14.36$ \\
\hline 17 & 4-hydroxybenzoic acid & $\sim$ LOD & $\sim$ LOD & n.d. & n.d. & n.d. & $4.9 \pm 0.1$ & n.d. & $8.2 \pm 0.2$ & n.d. & n.d & n.d & n.d & $0.2-13.2$ & $3.92 \pm 4.70$ \\
\hline 18 & Caffeic acid & $1.9 \pm 0.2$ & $4.3 \pm 0.1$ & $8.3 \pm 0.1$ & $11.1 \pm 0.3$ & $9.1 \pm 0.02$ & $8.4 \pm 0.1$ & $13.9 \pm 0.3$ & $12.6 \pm 0.3$ & $3.9 \pm 0.2$ & $4.5 \pm 0.3$ & $2.4 \pm 0.3$ & $4.3 \pm 0.01$ & $0.25-15.6$ & $7.55 \pm 3.92$ \\
\hline 19 & Gallic acid & $57.9 \pm 8.1$ & $103.5 \pm 3.5$ & $46.7 \pm 2.5$ & $59.8 \pm 0.9$ & $69.8 \pm 2.5$ & $16.3 \pm 0.6$ & $35.8 \pm 0.3$ & $53.7 \pm 2.0$ & $54.6 \pm 0.7$ & $111.8 \pm 15.7$ & $50.9 \pm 7.2$ & $9.1 \pm 5.5$ & $9.1-209.2$ & $55.40 \pm 30.49$ \\
\hline 20 & 3,4-Dihydroxybenzoic acid & $4.0 \pm 0.6$ & $\sim \mathrm{LOD}$ & $9.4 \pm 0.9$ & n.d. & $8.8 \pm 0.0$ & $6.7 \pm 0.4$ & $14.0 \pm 0.3$ & $21.45 \pm 0.9$ & $13.1 \pm 0.7$ & $2.3 \pm 0.3$ & $2.9 \pm 0.03$ & $4.6 \pm 0.1$ & $0.3-21.45$ & $7.04 \pm 5.12$ \\
\hline
\end{tabular}


Table 4: Polyphenol concentration levels $(\mathrm{mg} / \mathrm{L})$ in the three analyzed regions.

\begin{tabular}{clccc}
\hline $\mathrm{N}^{\circ}$ & Compound & Catalunya & La Rioja & Castilla-La Mancha \\
\hline 1 & 2-(4-Hydroxyphenyl)etanol & $77.7 \pm 12.7$ & $62.4 \pm 15.7$ & $77.9 \pm 14.7$ \\
2 & Resveratrol & $22.7 \pm 4.4$ & $23.9 \pm 1.6$ & $13.1 \pm 7.0$ \\
3 & Epicatechin & $58.0 \pm 22.7$ & $21.3 \pm 14.7$ & n.d. \\
4 & Catechin & $5.7 \pm 3.9$ & $2.2 \pm 2.6$ & n.d. \\
5 & Veratric acid & $9.1 \pm 6.4$ & $23.3 \pm 11.6$ & $16.8 \pm 10.2$ \\
6 & Homovanillic acid & n.d. & $13.4 \pm 8.1$ & n.d. \\
7 & Vanillin & $11.1 \pm 5.6$ & $11.9 \pm 4.9$ & n.d. \\
8 & t-Cinnamic acid & $7.2 \pm 3.1$ & $8.1 \pm 3.7$ & $4.9 \pm 1.2$ \\
9 & Sinapic acid & $n . d$. & $n . d$. & n.d. \\
10 & Quercitrin & $12.7 \pm 6.6$ & $12.7 \pm 9.1$ & $11.3 \pm 7.6$ \\
11 & Homogentisic acid & n.d. & n.d. & n.d. \\
12 & Syringic acid & $6.0 \pm 2.5$ & $5.6 \pm 2.0$ & $7.2 \pm 5.4$ \\
13 & Ferulic acid & $9.2 \pm 2.9$ & $11.0 \pm 2.6$ & $7.7 \pm 5.9$ \\
14 & Fisetin & $13.7 \pm 3.8$ & $15.2 \pm 2.2$ & $7.9 \pm 2.0$ \\
15 & p-Coumaric acid & $7.5 \pm 4.5$ & $13.9 \pm 3.7$ & $7.5 \pm 6.1$ \\
16 & Quercetin & $31.2 \pm 1.8$ & $31.5 \pm 1.6$ & $15.2 \pm 12.4$ \\
17 & 4-hydroxybenzoic acid & $10.7 \pm 3.5$ & $6.3 \pm 4.3$ & n.d. \\
18 & Caffeic acid & $7.9 \pm 3.0$ & $9.0 \pm 3.0$ & $6.2 \pm 3.8$ \\
19 & Gallic acid & $51.4 \pm 26.4$ & $49.4 \pm 21.4$ & $42.5 \pm 17.1$ \\
20 & 3,4-Dihydroxybenzoic acid & $3.0 \pm 2.0$ & $3.5 \pm 2.3$ & $12.6 \pm 3.7$ \\
\hline & Rexpress & &
\end{tabular}

Results expressed as: Mean of samples analyzed \pm standard deviation. 
Figure 1
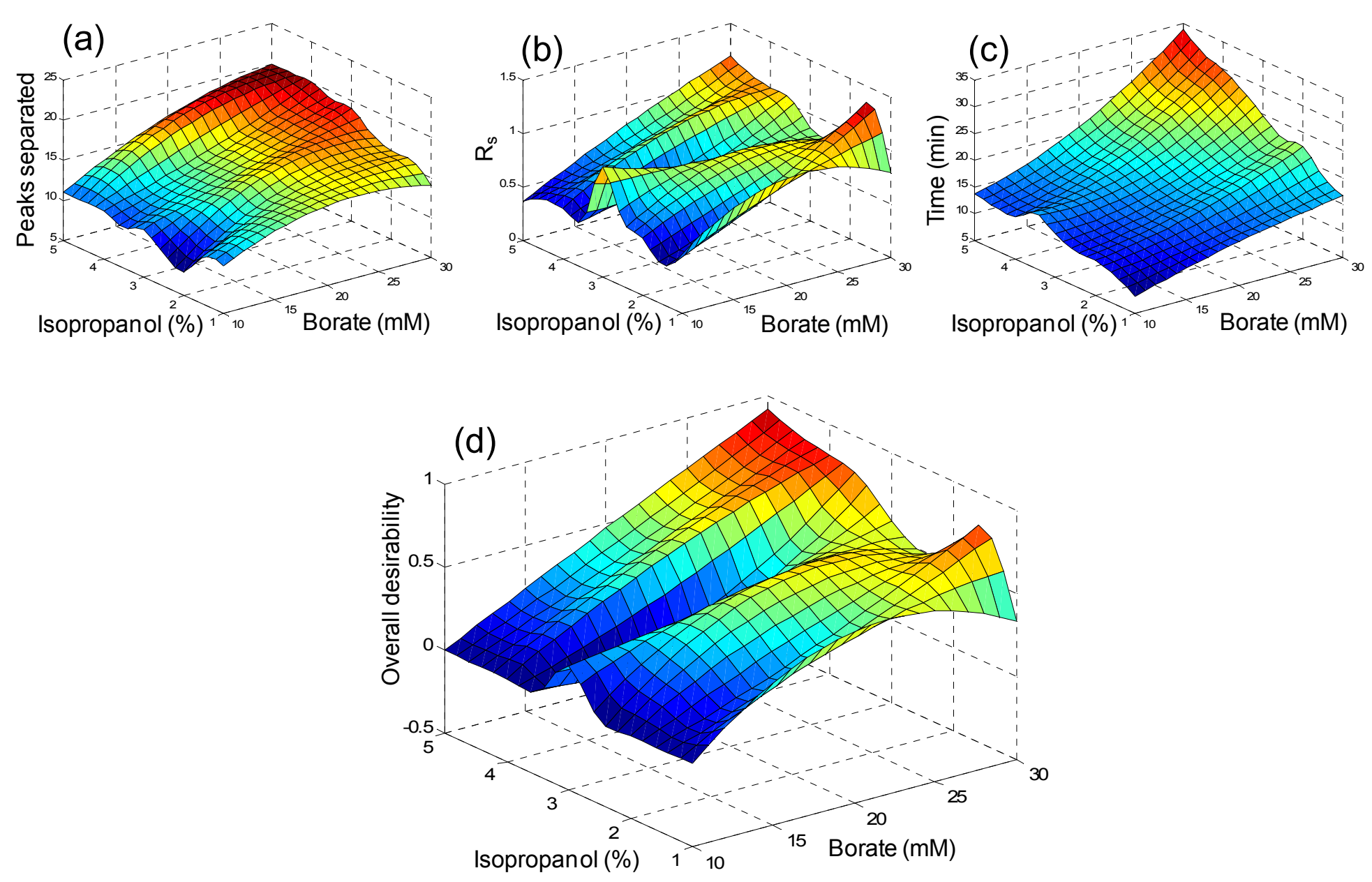
Figure 2

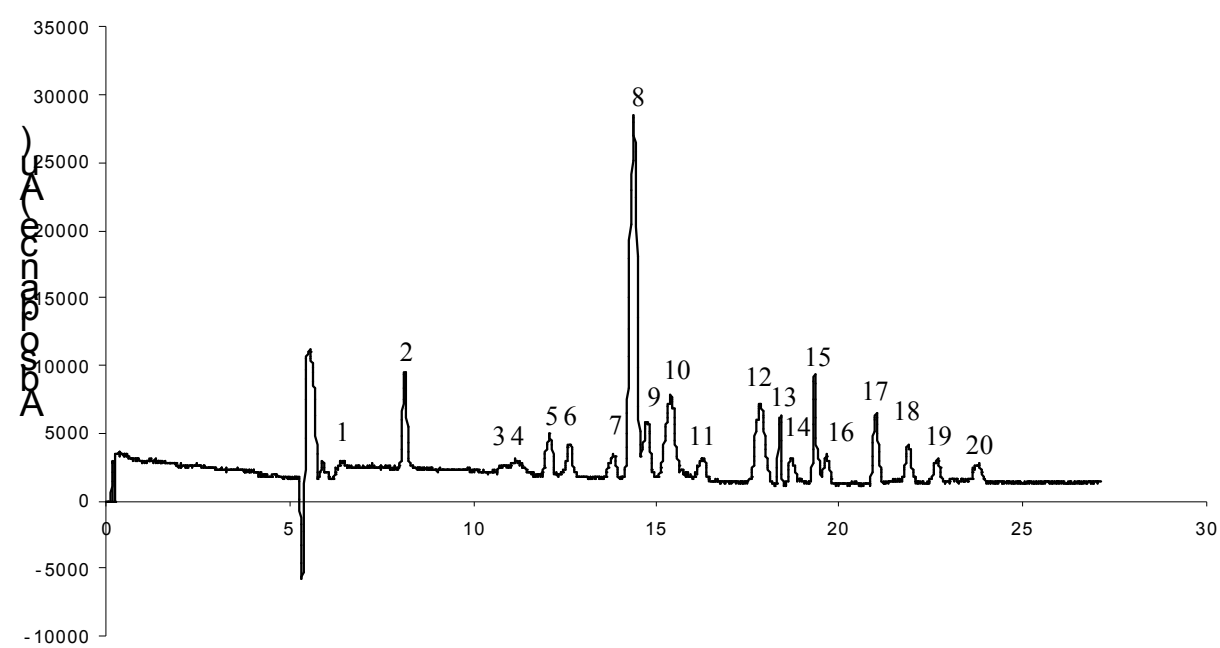

Time (min) 
Figure 3

(a)

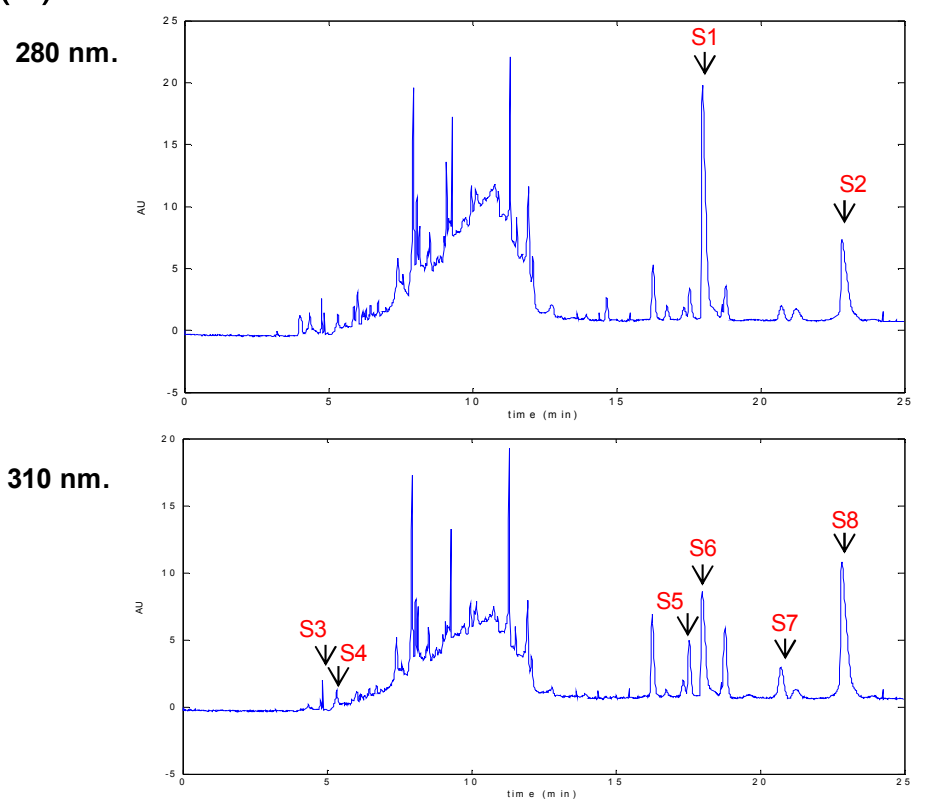

$370 \mathrm{~nm}$.

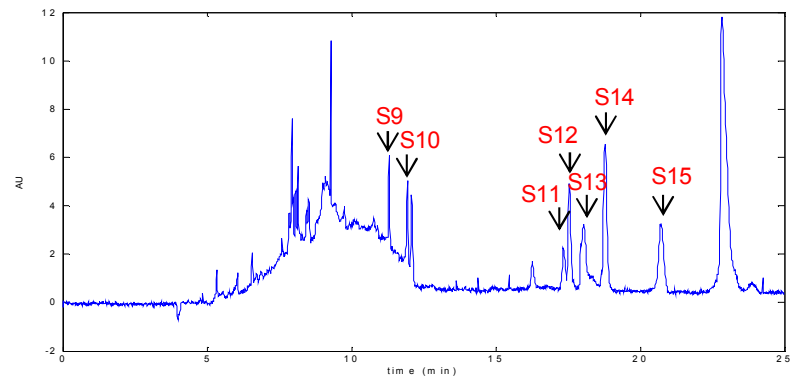

(b)
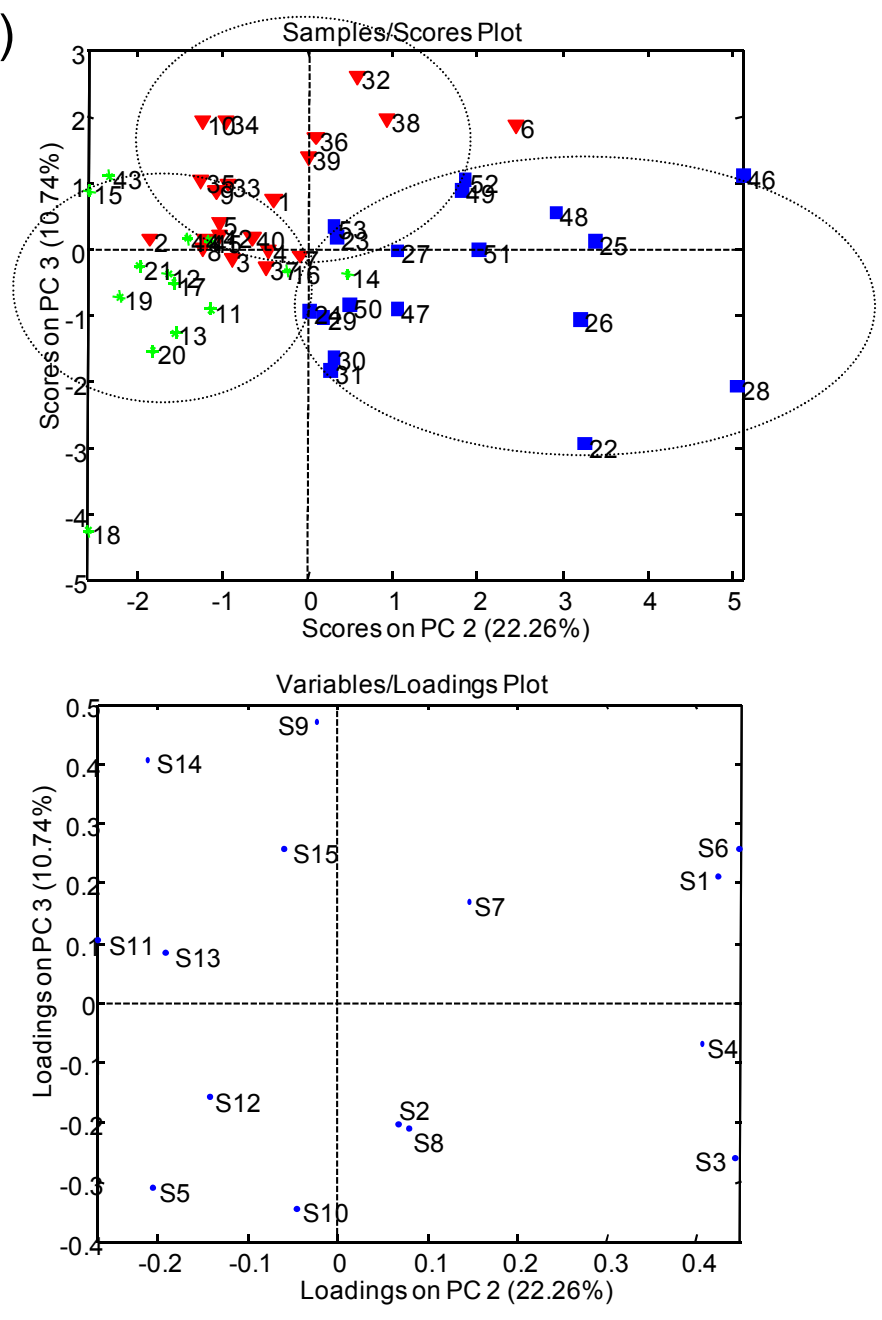
TOC Figure

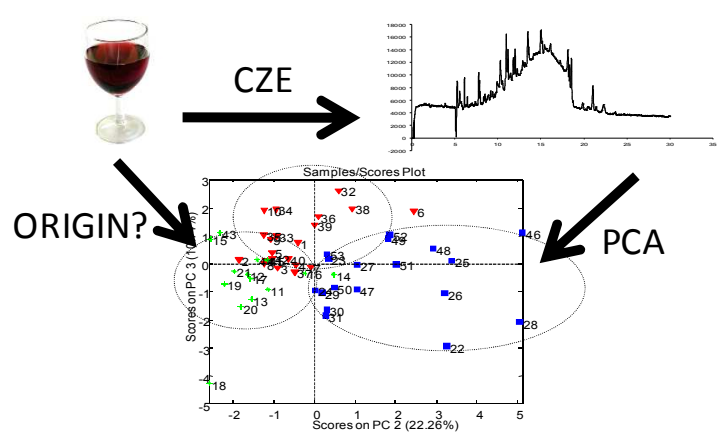

